\title{
Xanthomonas populi (ex Ridé 1958) sp. nov., nom. rev.
}

\author{
M. RIDÉ AND S. RIDÉ* \\ Station de Pathologie Végétale et Phytobactériologie, Institut National \\ de la Récherche Agronomique, 49070 Beaucouzé, Angers, France
}

\begin{abstract}
Because of an oversight, the name Xanthomonas populi (Ridé 1958) Ridé and Ridé 1978 was not included on the Approved Lists of Bacterial Names and therefore lost its nomenclatural standing. In this paper, the name is revived for application to the same taxon. A description of the taxon is given. Because no type strain was designated in the original publication, a neotype strain is proposed.
\end{abstract}

Xanthomonas populi was proposed (3) as a new combination for Aplanobacter populi (2), but no type strain was proposed. This defect could have been remedied at the time of preparation of the Approved Lists of Bacterial Names (4). Because of an oversight, this step was not taken (6), and the name was omitted from the Approved Lists.

A comprehensive phenotypic description $(3,5)$, summarized below, showed that the species $X$. populi is a distinct taxon within the genus Xanthomonas.

Xanthomonas populi (Ridé 1958) ex Ridé and Ridé 1978 nom. rev. (pop'u.li. M.L. n. Populus, generic name of poplar tree; M.L. gen. n. populi, of poplar). Gram-negative, obligately aerobic, straight rods that are sometimes slightly curved, are 0.4 to 0.6 by 1.5 to $2.9 \mu \mathrm{m}$, and are sometimes motile by means of a single polar flagellum. Strains produce xanthomonadin pigments; on media containing glucose, mucoid growth indicates the production of xanthans. The $\mathrm{G}+\mathrm{C}$ ratio is 62 to $65 \mathrm{~mol} \%$. Strains have been shown to be members of the Xanthomonas DNA-rRNA homology group (1). These data confirm that the organism is an authentic member of the genus Xanthomonas both in phenetic terms and in genomic terms.

The organism has an optimum growth temperature of 20 to $23^{\circ} \mathrm{C}$. Positive for esculin hydrolysis, alkaline reaction in milk, catalase production, and $\mathrm{H}_{2} \mathrm{~S}$ production from L-cysteine (but not from peptone). A hypersensitive reaction is induced in tobacco leaves. Negative in tests for oxidase, polygalacturonase, urease, and lecithinase activities, acetoin production, indole production, gelatin liquefaction, growth in the presence of $10 \%$ glucose, growth in media at $\mathrm{pH}<5.5$, growth in media containing more than 0.4 to $0.6 \% \mathrm{NaCl}$, and growth in media containing $0.005 \%$ triphenyltetrazolium chloride.

Acid is produced from D-fructose, D-galactose, D-glucose, mannose, sucrose, and trehalose, but not from L-arabinose, cellobiose, D-lactose, maltose, melibiose, raffinose, L-rhamnose, D-ribose, D-xylose, dulcitol, meso-erythritol, mesoinositol, mannitol, sorbitol, amygdalin, dextrin, inulin, or salicin.

Growth occurs with the following carbon sources without the addition of $0.05 \%$ Casamino Acids to the basal medium: $D$-glucose, D-galactose, D-mannose, sucrose, and fumarate. Growth does not occur with L-rhamnose, ethanol, i-butanol, D-alanine, L-alanine, L-asparagine, ethanolamine, L-leucine, L-isoleucine, norleucine, L-serine, L-threonine, L-valine, ac-

\footnotetext{
* Corresponding author.
}

etate, $n$-butyrate, citrate, L-glutamate, D-glycerate, 2-ketogluconate, mucate, propionate, or tartrate.

Growth is stimulated by L-cysteine, L-glutamate, and L-methionine, but not by L-alanine, L-arginine, L-asparagine, L-aspartate, L-glutamine, glycine, L-histidine, L-isoleucine, L-leucine, L-ornithine, L-phenylalanine, L-serine, L-threonine, L-tyrosine, L-tryptophane, or L-valine.

None of the following amino acids is utilized as the sole source of carbon: L-alanine, L-arginine, L-asparagine, L-aspartate, L-cysteine, L-glutamate, L-glutamine, glycine, L-histidine, L-hydroxyproline, L-isoleucine, L-leucine, L-lysine, L-methionine, L-ornithine, L-phenylalanine, L-proline, Lserine, L-threonine, L-tyrosine, L-tryptophan, and L-valine.

None of the following amino acids is used as the sole source of $\mathrm{C}$ and $\mathrm{N}$ : L-alanine, L-asparagine, L-glutamine, L-glutamate, L-hydroxyproline, and L-proline.

Growth occurs in the presence of antimony sodium tartrate, $\mathrm{CuI}_{2}$, fucidin, $\mathrm{KSCN}$, oxacillin, oleandomycin, penicillin, sulfafurazole, and salicylate, but not in the presence of ampicillin, aureomycin, bacitracin, cephaloridin, chloramphenicol, dimethylchlortetracycline, erythromycin, gentamicin, kanamycin, neomycin, nitrofurantoin, novobiocin, paranomycin, spiramycin, streptomycin, terramycin, tetracycline, or thiophenicol.

Tests which give variable results (5) are not described here. Van den Mooter and Swings (5) have described a comparative study in which determinative tests for Xanthomonas species, including $X$. populi, were described.

The following strains were part of the collection on which the description given above was based: strains CFBP 1818 (= LMG 969 = NCPPB 2961), CFBP 1820 (= ICMP $5831=$ LMG 5745 = NCPPB 2963), CFBP 1821 (= ICMP $5830=$ NCPPB 2952), CFBP 1822 (= ICMP 5829 = NCPPB 2951), CFBP 1824 (= LMG $972=$ NCPPB 2955), CFBP 1825 (= ICMP 5827 = NCPPB 2954), CFBP 1826 (= ICMP 5817 = LMG 973 = NCPPB 2962), CFBP 1829 (= LMG 975), CFBP 1830 (= LMG 974), and LMG 977.

We propose that Xanthomonas populi (Ridé 1958) Ridé and Ridé 1978 should be reinstated as a revived name, Xanthomonas populi (Ridé 1958) sp. nov., nom. rev., and that the neotype strain should be strain CFBP 1817 (= ICMP 5816 = LMG 5743 = NCPPB 2959).

\section{REFERENCES}

1. De Vos, P., and J. De Ley. 1983. Intra- and intergeneric similarities of Pseudomonas and Xanthomonas ribosomal ribonucleic acid cistrons. Int. J. Syst. Bacteriol. 33:487-509.

2. Ridé, M. 1958. Sur l'étiologie du chancre suintant du peuplier. 
C.R. Acad. Sci. 246:2795-2798.

3. Ridé, M., and S. Ridé. 1978. Xanthomonas populi (Ridé) comb. nov. (syn. Aplanobacter populi Ridé), specificité, variabilité, et absence de relations avec Erwinia cancerogena Ur. Eur. J. For. Pathol. 8:310-333.

4. Skerman, V. B. D., V. McGowan, and P. H. A. Sneath (ed.). 1980. Ap- proved lists of bacterial names. Int. J. Syst. Bacteriol. 30:225-420.

5. Van den Mooter, M., and J. Swings. 1990 . Numerical analysis of 295 phenotypic features of 266 Xanthomonas strains and related strains and an improved taxonomy of the genus. Int. J. Syst. Bacteriol. 40:348-369.

6. Young, J. M. Personal communication. 